\title{
Frontera y migración en el norte de Chile a partir del análisis de los censos de población. Siglos XIX- XXI ${ }^{1}$
}

\author{
Marcela Tapia Ladino ${ }^{2}$
}

\begin{abstract}
RESUMEN
Los estudios sobre frontera y migración limítrofe son un ámbito de exploración que permiten ampliar la mirada sobre la movilidad humana en tanto la inclusión del fenómeno migratorio regional no se da desconectado de lo que ocurre en otras zonas del país ni de los países circunvecinos. Este trabajo pretende aportar a un conocimiento que incluye la larga duración de las migraciones fronterizas en Chile así como la atención por el fenómeno reciente de aumento de migrantes sudamericanos en el centro del país. Se postula que la migración limítrofe de peruanos y bolivianos ha sido central para en la configuración de la sociedad tarapaqueña ligada fundamentalmente a los ciclos económicos y a las ventajas que ofrece el cruce de las fronteras en distintos momentos históricos. En este sentido los censos de población son la fuente principal de información y el punto de partida de cualquier estudio sobre migraciones fronterizas, no obstante se verifica la necesidad de ampliar la exploración de otras estadísticas complementarias que permitan avanzar hacia un conocimiento más cabal sobre las dinámicas migratorias en los espacios fronterizos.
\end{abstract}

Palabras clave: Frontera, migración limítrofe, región.

\begin{abstract}
Studies on frontier and border migration are an area of exploration that help to increase the look on human mobility given that the inclusion of regional migration phenomenon is not given in a disconnected way from what happens in other areas of the country or neighboring countries. This work aims to provide knowledge that includes the long duration of border migration in Chile, as well as care for the recent phenomenon of increasing migration of South American migrants in the center of the country. It is postulated that migration from Peruvian and Bolivian border has been central to the configuration of the tarapaquenian society fundamentally tied to economic cycles and the benefits of the border crossing at different historical moments. In this sense, population censuses are the main sources of information and the starting point of any study on border migrations, however we can see the need to expand the exploration of other complementary statistics in order to advance towards a fuller understanding of the dynamics migration in the border areas.
\end{abstract}

Key words: Border, border migration, region.

\footnotetext{
1 Este trabajo es producto del proyecto interno DI 0031/09 financiado por la Dirección General de Investigación de la Universidad Arturo Prat. Asimismo esta investigación se ubica en el marco del Proyecto ECOSCONICYT C008H02, proyecto que ha sido ejecutado por el Instituto de Estudios Internacionales INTE de la Universidad Arturo Prat y el Instituto de Geografía
}

Alpina de la Universidad Joseph Fourier, Francia. La autora agradece a Dianela Arroyo por su colaboración en la confección de mapas y a Michel Parra en el trabajo de explotación de los censos analizados.

2 Instituto de Estudios Internacionales (INTE), Universidad Arturo Prat (Chile).

E-mail: marcela.tapia@unap.cl 
De un tiempo a esta parte, Chile se ha convertido en el destino preferente de la migración de origen sudamericano, especialmente de tipo fronterizo, hecho que ha motivado la proliferación de estudios de tesis y publicaciones preocupadas por este tema (Cano y Sofia, 2009). Este interés se relaciona especialmente por el aumento de la presencia del colectivo peruano en la capital chilena y con la novedad que genera este arribo al centro del país. Sin embargo, dicha mirada revela al mismo tiempo la escasa atención que los investigadores han puesto en los procesos migratorios de largo aliento situados preferentemente en las regiones periféricas (Gavilán y Tapia, 2006; Norambuena, 2002).

El objetivo último de este trabajo es situar el fenómeno migratorio chileno reciente desde el espacio fronterizo, específicamente desde el enfoque regional en un marco temporal mayor que supere la mirada en la coyuntura. Para alcanzar este objetivo se considera el caso de las migraciones fronterizas presentes en Tarapacá, a través del análisis de los censos de población de los siglos XIX y XXI. La Región de Tarapacá -el 2007 se crea la XV Región de Arica-Parinacota- por largo tiempo fue un espacio trinacional, con un pasado de disputas y reclamos, pero que posee a nivel territorial una historia de cooperación e intercambios formales e informales fronterizos así como una cultura ancestral común de origen aymara (Marteles, 2009: 175).

La metodología utilizada en este trabajo corresponde a la explotación de los datos censales de nivel regional y nacional y la revisión bibliográfica especializada en el tema. Si bien el objeto de estudio se ubica en el espacio regional, el trabajo tiene en cuenta la dimensión nacional en tanto los fenómenos no se dan desconectados con el resto del país. El afán es poner en perspectiva el fenómeno para así captar las particularidades que adquiere en el espacio fronterizo.

El trabajo que se desarrolla a continuación se organiza de la siguiente manera: en la primera parte se analizan los conceptos de espacio fronterizo, frontera y migración y el debate actual en que se encuentran dichas nociones. El segundo apartado corresponde al análisis de los censos como fuente para el estudio de las migraciones fronterizas, sus ventajas y limitaciones. En el tercer y cuarto epígrafe se revisa la historia de la migración fronteriza en Chile y en Tarapacá, respectivamente, desde fines del siglo XIX hasta principios del XXI. En el quinto apartado se lleva a cabo el estudio de las tres últimas rondas de censos en Tarapacá, para lo cual se establecen los principales rasgos detectados en el análisis.

\section{Espacio fronterizo, frontera $y$ migración}

En esta parte se revisa el vínculo teórico entre migración y frontera y las implicancias que ha tenido la definición de una y otra para el estudio y conteo de la población extranjera de origen limítrofe. Como punto de partida es preciso señalar que los espacios fronterizos se constituyen en un lugar desde donde mirar y analizar los fenómenos sociales e históricos de distinto nivel que cada vez más escapan al marco de análisis de lo nacional y que a menudo son desbordados por los fenómenos que allí ocurren. Uno de estos fenómenos lo constituyen las migraciones fronterizas y la variedad de movimientos de población que se desarrollan en estos ámbitos, entre ellos migración circular, el tránsito de comerciantes o el turismo comercial o médico, por mencionar algunos (Gelbman \& Timothy, 2011; Hinojosa, 2000; Llanque, 2011; Sassone y Cortés, 2010). Estos movimientos ponen a prueba nociones como nación, cultura e identidad, puesto que las comunidades que habitan los espacios fronterizos se encuentran en una realidad más compleja que en otras regiones del país al estar alejadas del centro y en el medio, o entre dos o más sociedades, sistemas económicos y niveles de desarrollo (Gelbman \& Timothy, 2011).

La discusión acerca del concepto de frontera está en curso y no ha supuesto consensos en torno a una sola definición. En este sentido se encuentran distintas acepciones en el campo de las Ciencias Sociales. Para la Antropología la idea de frontera a menudo alude a discontinuidades entre grupos humanos -de género, de generación y cultura- (Bartolomé, 2008). Para la historia, frecuentemente hace referencia a una delimitación estatal y territorial, que separa a sociedades internamente homogéneas unidas por una lengua, un terri- 
torio y un pasado común establecido en un momento histórico (Beck, 2008; Pries, 2002). En el caso de la Geografía, tradicionalmente esta disciplina conceptuó las fronteras como líneas de demarcación entre unidades que difieren objetiva o subjetivamente (Van der Velde \& Van Naerssen, 2010: 3), en este caso como delimitación del territorio que separa a la población de un lado y otro del límite que puede ser interno e internacional (Hevilla, 1998; Hevilla y Zusman, 2008). En general, se trata de un concepto polisémico que se usa para denominar realidades fácticas, metafóricas o imaginarias construidas social y disciplinariamente (Bartolomé, 2008: 36).

En el ámbito territorial y político, a partir del Tratado de Westfalia (1648) se sentó la tradición que concibe las fronteras como demarcadores de los Estados nacionales y de las sociedades que las habitaban. Esta noción ha prevalecido por largo tiempo, incluso más allá de las interpretaciones optimistas que postulan el desdibujamiento de los límites o su pérdida de importancia (Guillén, 2001). La interpretación de las fronteras como separadores de los Estados decimonónicos fue concebida bajo una lógica monista existencial en la idea de construir una ciudadanía idéntica donde las fronteras fueron entendidas como el deslinde que contiene a la nación. A la naturalización del Estado-nación en el análisis social se le ha denominado nacionalismo-metodológico, hecho que alude a "la tendencia a aceptar al Estado-nación y sus fronteras como un elemento dado en el análisis social" (Wimmer \& Schiller, 2003: 576). El sustrato epistemológico que subyace en esta definición concibe a los países como unidades estancas que equiparan la sociedad al Estado-nación.

De acuerdo a lo anterior, la noción de frontera que persiste en la actualidad corresponde a la interpretación heredada de la construcción de los Estados nacionales del siglo pasado que alude fundamentalmente a los contornos del territorio de los Estados nacionales, donde estos ejercen soberanía (Medina, 2006: 14). Sin embargo, desde el siglo XIX a la fecha se viene discutiendo el concepto de frontera en el marco del debate sobre la globalización y al lugar que le corresponde en ella a la movilidad humana. En términos condensados, podemos señalar que la discusión que vincula frontera y globalización discurre entre dos grandes cuerpos de interpretación. En un lado se sitúan quienes afirman que la globalización perfora las fronteras y que se asiste al debilitamiento de su función separadora (Guillén, 2001; Shamir, 2005). En este sentido se señala que el mundo está cada vez más interrelacionado, gracias al avance de las comunicaciones, el abaratamiento del transporte y las posibilidades que entrega internet, entre otros aspectos. Se trata de una de una mirada optimista de los alcances de la globalización donde las fronteras se vuelven porosas (Leontidou et al., 2005), aliterales (Garduño, 2002) o perforadas (Pries, 2002).

En el otro lado del debate se sitúan aqueIlos que sostienen que la globalización ha sido definida fundamentalmente como fenómeno económico, financiero y comunicacional y que ello no supone necesariamente el debilitamiento de las fronteras, especialmente cuando analizamos el movimiento de personas en distintas latitudes. Por el contrario, lo que se observa es un fenómeno de fronterización (Arango, 2007), es decir, de cierre de fronteras y endurecimiento de los requisitos para la libre circulación humana. Ambos debates están vigentes, se discuten y se critican mutuamente, nos obstante existe relativo acuerdo en señalar que estos procesos no se dan por separado ni de manera unidireccional, sino que con frecuencia se superponen (Guillén, 2001). Desde otros sectores surge un discurso que discute a ambos cuerpos interpretativos y advierte que las viejas jerarquías nacionales y sus límites no desaparecen del todo, sino que surgen nuevas escalas -regiones fronterizas y transfronterizas- que ponen a prueba las nociones históricas que sustentaron la construcción de los Estados nacionales (Sassen, 2007). Por tanto, en la actualidad se asiste a la multiplicación de actores no estatales y a la proliferación de procesos transfronterizos que generan cambios y tensionan las competencias, las facultades de las instituciones nacionales y los sustratos históricos que le han dado vida.

En esta escenario se asiste a un renacimiento del estudio de las fronteras en el contexto de los discursos globalizadores que discuten la pérdida o no de importancia de los límites (Newman, 2006). Tradicionalmente el estudio de las fronteras había sido abordado 
desde "arriba hacia abajo", sin embargo, cada vez más se considera la mirada desde "abajo hacia arriba" que recoge las experiencias individuales y las formas en que las fronteras impactan en las prácticas diarias de las personas que las habitan (Newman, 2006: 143).

En América Latina, los movimientos limítrofes de población son fenómenos recientes en términos históricos, puesto que las definiciones geográficas de las delimitaciones territoriales se remontan a la fundación de los Estados-nacionales del siglo XIX. En este contexto, la noción que ha predominado de las migraciones ha hecho alusión fundamentalmente al cambio de residencia de un Estadonación a otro distinto al de nacimiento. Estos cambios son captados por los sistemas estadísticos nacionales, entre ellos los censos de población y los registros administrativos. De modo que la conceptualización de los movimientos de población transfronterizos se ha sustentado en una definición de la sociedad nacional como un contenedor, es decir, en el entendido "que los contornos de la sociedad coinciden con los del estado-nación" (Llopis, 2007: 105). Estos supuestos han impactado en la forma de estudiar y definir las migraciones internacionales porque que se han basado fundamentalmente en el criterio de residencia y nacionalidad a la hora de contar extranjeros. No obstante estas limitaciones, los censos de población siguen siendo la fuente central de información migratoria con la que contamos en la actualidad (Martínez, 2008: 100).

\section{Los censos de población como fuentes para el estudio de las migraciones fronterizas}

Una de las dificultades encontradas a la hora de estudiar las migraciones es establecer la magnitud del fenómeno y su evolución en el tiempo. La compresión y análisis del fenómeno migratorio depende casi siempre de los datos estadísticos. La carencia de registros continuos de población en América Latina o fuentes alternativas confiables para medir la migración fronteriza e internacional explica el uso generalizado de los censos de población (Canales et al., 2010).
Para la Comisión Económica para América Latina y el Caribe (CEPAL), la información que entregan los censos de población se ajusta a la definición tradicional de migración internacional, es decir, se conceptúa como el traslado de residencia de las personas de un país a otro ${ }^{3}$. Esta información se obtiene de unas pocas preguntas que buscan cuantificar a las personas que han ingresado al país con el fin de residir por al menos un tiempo. Asimismo, se obtiene información sobre los atributos sociodemográficos de los encuestados que declaran tener una nacionalidad distinta a la chilena y que se encuentran residiendo en el país al momento de responder el censo. En general, la información que entregan los censos respecto de los migrantes, corresponde al stock de extranjeros que residen en el país en un momento dado y a sus rasgos sociodemográficos (Martínez, 1999, 2008).

Los censos de población, como fuente estadística para el estudio de las migraciones, se caracterizan por la universalidad y periodicidad en su aplicación, regularmente cada diez años. En Chile se han aplicado de manera sistemática desde la segunda mitad del siglo XIX a la fecha, por tanto se trata de una fuente confiable que permite realizar series y observar las variaciones de los colectivos migrantes en el tiempo. Sin embargo, dada la periodicidad decenal con que se aplican, tienden a perder vigencia con el paso de unos pocos años al no captar los movimientos que ocurren en el periodo intercensal. Asimismo, al tomar en cuenta la nacionalidad, no es posible saber en qué condición se encuentran las personas encuestadas, es decir, si son cuentan con la residencia o están de manera irregular (Martínez, 2008). Con todo, los censos de población, con sus ventajas y desventajas, siguen siendo "la fuente matricial de información migratoria" (Martínez, 2008: 100).

\footnotetext{
3 Para efectos de los Censos, el concepto de Extranjero Residente hace referencia a personas que declaran que nacieron en otro país y que tienen residencia habitual en una determinada comuna del país. Los Inmigrantes, por su parte, son definidos como aquellas personas que al momento de ser censadas residen en el lugar en que les ha sido aplicada la encuesta, u otra región del país, y que cinco años atrás, tenía una residencia permanente en una región o país diferente (INE, censos de población).
} 


\section{Migración fronteriza en Tarapacá y en Chile: hitos y rasgos generales}

Como se ha señalado, los censos son el punto de partida que permiten obtener una panorámica general de las migraciones fronterizas y establecer las características específicas que adoptan en el tiempo y en el espacio geográfico. Para una mayor comprensión del análisis de los datos, se tendrán en cuenta dos niveles, el regional y el nacional, los cuales no se consideran como dimensiones separadas, sino como parte de un conjunto integrado de escalas en los que se reconocen jerarquías de una sobre otra. En este marco, dada la particularidad del espacio fronterizo tarapaqueño, se tiene en cuenta el carácter transfronterizo de la región, es decir, de la existencia de un espacio influenciado por la proximidad y complementariedad de los territorios vecinos adyacentes (Newby, 2006). Por tanto, se considera en el análisis las referencias a dicho espacio más allá de la noción de límite como demarcador.

Como punto de partida, la revisión de los datos censales advierte que desde fines del siglo XIX hasta hoy, es posible distinguir dos momentos relevantes de presencia extranjera de origen limítrofe a nivel nacional. El primero se sitúa luego del fin de la Guerra del Pacífico y la incorporación de Tarapacá al territorio chileno, hasta el final del ciclo salitrero, en los años 30; y el segundo, corresponde a la migración reciente, que se observa a partir de los años noventa al siglo XX en adelante, con especial presencia en el centro del país.

En una segunda mirada de los datos, en la escala regional, es posible apreciar que la presencia de extranjeros de origen fronterizo, es un rasgo permanente en Tarapacá. De hecho, los mismos censos advierten que el peso de extranjeros limítrofes respecto de la población total de Tarapacá ha sido significativo y mayor al porcentaje nacional durante todo el periodo revisado (Ver Cuadro $N^{0} 1$ ). No obstante, se observan variaciones que siguen la tendencia de la escala nacional -señalada más arriba-, según lo cual se advierte un aumento significativo en las últimas décadas del siglo XIX y primera mitad del siglo XX, para decaer a fines del siglo XX y volver a aumentar entrada la actual centuria. Sin embargo, se constata que este segundo momento no tiene la intensidad del primero a escalal regional.

En el Cuadro $\mathrm{N}^{\circ} 1$ se aprecia que en general durante el siglo XX la presencia de extranjeros en Tarapacá fue siempre significativa respecto de la población regional y mayor en términos proporcionales respecto del porcentaje nacional. Esta tendencia se mantuvo incluso en épocas de crisis, como fue durante el fin del ciclo salitrero y durante el declive de la llegada de inmigrantes durante el régimen militar. Por lo tanto, es posible afirmar que dada la naturaleza fronteriza de la región y la existencia de ciclos económicos regionales, la circulación y constante interacción de las poblaciones contiguas ha sido un fenómeno permanente y constitutivo de su realidad.

Extranjeros fronterizos en Tarapacá: fines del siglo XIX y principios del XX

Una característica central de las regiones colindantes es la presencia de población fronteriza que, en el caso del extremo norte de Chile, se aprecia desde la incorporación de esos territorios al Estado chileno. En Tarapacá la población peruana pasó a formar parte del Estado chileno a través del Tratado de Ancón de 1883, situación que constituyó a la población nativa en extranjeros y dio inicio a un proceso de chilenización de la zona (González, 2002, 2004). El estatus jurídico de Taparacá ha sufrido cambios en la composición de las provincias y territorios que incluye a lo largo del siglo XX y XXI. La situación de la zona comprendida entre Tacna y Arica se resolvió en el Tratado de Lima de 1929, luego de un largo litigio según el cual se acordó la "partija" de ambas provincias (Tacna para Perú y Arica para Chile) y una nueva delimitación del territorio (González, 2008; González, 2009a). A partir de este momento los censos de población consignan una presencia 
relevante de extranjeros en la región -especialmente peruanos-, de los cuales mucho eran originalmente sus habitantes ${ }^{4}$.

Una vez incorporado Tarapacá al territorio chileno y hasta el fin del ciclo salitrero, este espacio se convirtió en el destino de numerosas personas provenientes de distintas latitudes, de Chile y del mundo, lo que dio vida a la sociedad pampina y la configuración de una sociedad multinacional (González, 2002). En ese contexto, las poblaciones aledañas a Tarapacá fueron atraídas por las oportunidades laborales que ofrecían la explotación del salitre y la necesidad de proveer de mano de obra a la exigente industria. El enganche fue el mecanismo por el cual llegaron a la región principalmente varones alentados por la oportunidad de ganar dinero, entre ellos peruanos y bolivianos (González, 2002; Pinto, 1997). Muchos de los peruanos consignados en los censos eran peruanostarapaqueños y otros llegaron a trabajar a las salitreras una vez iniciada la expansión salitrera.
Cuadro $\mathrm{N}^{\circ} 1$

Proporción de extranjeros sobre la población de Tarapacá ${ }^{5}$ y Chile 1885-2002

\begin{tabular}{|l|r|r|}
\hline Censos & $\begin{array}{c}\text { Porcentaje de ex- } \\
\text { tranjeros respecto } \\
\text { de población de } \\
\text { Tarapacá }\end{array}$ & $\begin{array}{c}\text { Porcentaje de } \\
\text { extranjeros res- } \\
\text { pecto de la po- } \\
\text { blación nacional }\end{array}$ \\
\hline 1885 & 51,9 & 3,5 \\
\hline 1895 & 28,5 & 2,9 \\
\hline 1907 & 39,8 & 4,2 \\
\hline 1920 & 15,3 & 3,2 \\
\hline 1930 & 12,0 & 2,5 \\
\hline 1940 & 6,8 & 2,1 \\
\hline 1952 & 5,9 & 1,6 \\
\hline 1960 & 5,0 & 1,4 \\
\hline 1970 & 8,5 & 1,0 \\
\hline 1982 & 1,9 & 0,7 \\
\hline $1992^{*}$ & 1,8 & 0,8 \\
\hline $2002^{* *}$ & 3,0 & 1,2 \\
\hline
\end{tabular}

* Incluye extranjeros residentes y transeúntes.

** Incluye solo extranjeros residentes.

Fuente: Elaboración propia. INE Censos de Población
4 La incorporación del nuevo territorio implicó la puesta en vigencia de los códigos legales chilenos y abolición de las leyes peruanas. En 1887 se decretó la Ley de adscripción a la nacionalidad peruana o chilena de los residentes tarapaqueños, según el cual "Se concede, contados desde que esta ley comience a regir en la provincia de Tarapacá, para que las personas nacidas en ese territorio antes del 21 de mayo de 1884 y actualmente residente en él, establezcan su nacionalidad peruana con arreglo a lo dispuesto en el artículo 14 de la ley del 31 de octubre de 1884" (Aguilera, 2003: 25).
5 Taparacá ha sufrido cambios en la composición de las provincias y territorios que incluye a lo largo del siglo XX y XXI. De acuerdo al Censo de 1885, 1895 y 1907 la provincia de Tarapacá incluía los departamentos de Pisagua y Tarapacá (Comisión Central del Censo, 1907, Oficina Central de Estadística, 1885, 1895). Según el censo de 1920 el departamento Tarapacá comprendía a las provincias de Tocopilla, Antofagasta y Taltal (Dirección General de Estadística, 1920). En el censo de 1930 y 1940 Tarapacá comprendió a los departamentos de Arica, Pisagua e Iquique (Dirección General de Estadística, 1930). En el censo de 1960 Tarapacá incluyó a las provincias de Arica e Iquique. En el censo de 1982, 1992 y 2002 la región estaba comprendida por las provincias de Arica, Parinacota e Iquique. En este caso solo se considera a la región de manera ilustrativa con el objeto de establecer series y establecer comparaciones teniendo claro que las regiones chilenas han experimentado cambios en la división política y administrativa durante los dos últimos siglos (Comisión Central del Censo, 1907; Dirección General de Estadística, 1920; Dirección General de Estadística, 1930; Oficina Central de Estadística, 1885; Oficina Central de Estadística, 1895). 
El proceso de chilenización iniciado en la zona a través de la instalación de escuelas, símbolos patrios y autoridades chilenas, no supuso problemas en la convivencia entre chilenos y peruanos hasta 1910. Fue a partir del oncenio del presidente peruano Augusto Leguía (1919-1930) y en el marco del litigio por las provincias "cautivas" de Arica y Tacna, que se vivió uno de los capítulos más oscuros de la historia tarapaqueña. Se trata del proceso chilenización compulsiva que consistió en violencia, acciones punitivas en contra de los peruanos-tarapaqueños que en muchos casos terminó con la expulsión (González, 2004). De hecho, los censos de 1907 a 1920 advierten una caída del volumen de peruanos en Tarapacá, que pasó de 23.574 personas a 12.095, lo que significa una disminución de casi la mitad $(-48 \%)$ del total de ese colectivo (INE, Censos respectivos).

Siguiendo el análisis de los censos, se aprecia que el de 1907 fue el que registró mayor presencia extranjera a nivel nacional con un $4,2 \%$ del total de la población del país. En el caso de Tarapacá, los extranjeros residentes alcanzaron una proporción del $38,9 \%$ del total de la población de la provincia, correspondiente a 43.774 personas. Del total de extranjeros que registró el censo analizado, el 86\% correspondió a sudamericanos que en su mayoría eran de origen fronterizo, preferentemente peruanos y bolivianos. Al observar los grupos más numerosos en el mismo censo, se advierte que la primera mayoría correspondió a los peruanos, con 23.574 personas, lo que se traduce en el $54 \%$ del total de extranjeros de Tarapacá para ese año. Le siguen los bolivianos con 12.528 personas, es decir, un $29 \%$ del total de extranjeros de la provincia. Muy por detrás se encontraban los argentinos (556 personas) que junto a los ecuatorianos no sobrepasaron el 1,6\% del total de extranjeros (INE, Censos respectivos; Norambuena, 2002).

El peso de la población extranjera en los censos de Tarapacá se mantuvo por sobre los dos dígitos porcentuales hasta 1930, situación que coincide con el fin del ciclo salitrero. Sin embargo, dentro del universo de extranjeros, los de origen fronterizo mantuvieron una preeminencia durante todo el siglo XIX, incluso en épocas de declive migratorio. Como se señaló más arriba, la mayor proporción de extranjeros de origen fronterizo se explica por la reciente incorporación de este territorio al Estado de Chile y por la importancia que alcanzó la población limítrofe peruana y boliviana en la actividad del nitrato (González, 1995, 2002, 2009b). En este contexto se aprecia que a pesar de la notoriedad que alcanzaron los extranjeros de origen europeo en la actividad salitrera, el peso de la migración fronteriza fue mucho mayor en términos absolutos ${ }^{6}$.

En general, se observa que la presencia de población extranjera de origen limítrofe ha sido permanente y significativa en términos relativos durante el siglo $X X$ y principios de la actual centuria. La creciente incorporación al mercado mundial a través de la creación de la Zona Franca de Iquique, ZOFRI (1975), el fuerte impulso de la actividad minera en la región en las últimas décadas y el impacto de los procesos de integración económica regional, como el impulsado por el MERCOSUR (1991), ha dado lugar a un intenso movimiento de personas y mercancías en el espacio fronterizo del extremo norte chileno. Se trata de un espacio donde existe contacto habitual con las regiones y poblaciones vecinas, lo que se traduce en un intenso trajín fronterizo ${ }^{7}$. No obstante, hasta hace poco tiempo estos temas no habían sido motivo de preocupación de las Ciencias Sociales por el carácter marginal y secundario de las zonas fronterizas. Lentamente se ha producido "un giro inédito en la reflexión sobre la realidad latinoamericana: el tratamiento de la periferia como centro" (Jaquet, 2008: 34).

\footnotetext{
6 Existen trabajos específicos que abordan el tema de la migración fronteriza en Tarapacá que han cubierto el periodo del ciclo salitrero (Calle, 2008; Castro, 2010; González, 2008; González, 2002, 2009b).

7 Según fuentes de prensa entre el año 2001 y 2008, la Región de Arica-Parinacota ha duplicado el movimiento migratorio de 2.614 .653 personas a 4.640.658. Según la misma fuente "entre junio de 2008 y mayo de 2009 entraron y salieron 4.558 .188 personas por las avanzadas o puestos fronterizos de la región, es decir, 438.364 más que por el Aeropuerto Comodoro Arturo Merino Benítez y 2.755.727 más que por el Paso Internacional Los Libertadores (Rozas, 5 de junio de 2009).
} 
Extranjeros fronterizos en el centro del país: fines del siglo $X X$ y principios del siglo XXI

El segundo momento que interesa revisar y que constituye el cuerpo central de este trabajo, corresponde al análisis de los censos de 1982, 1992 y 2002. Como se señaló, el interés por este periodo se relaciona con el aumento de la migración fronteriza en los últimos años y con la notoriedad que han alcanzado en el centro del país. A nivel nacional los estudios advierten una disminución de los extranjeros de origen europeo, a lo largo del siglo $\mathrm{XX}$, tanto en términos absolutos como en términos relativos, sin olvidar que dicha migración no tuvo la preponderancia que alcanzó en otros países de América Latina (CEPAL/CELADE, 2006). Asimismo, es necesario relevar que el porcentaje de población extranjera en los censos estudiados apenas supera en $1 \%$ a nivel nacional en las tres últimas rondas de censos y que el saldo migratorio sigue siendo negativo. Por lo tanto, de acuerdo a las fuentes que seguimos, no es posible afirmar que Chile se ha convertido aún en un país de inmigrantes. Queda por ver los resultados del censo de población 2012 cuyos resultados someterán a prueba la realidad migratoria chilena.

Con todo, la preocupación por la migración reciente se relaciona con su composición, cambio en la dirección y la aceleración que ha experimentado en las dos últimas décadas (Solimano y Tokman, 2008). En este segundo momento de auge migratorio fronterizo, se vincula con el contexto latinoamericano y la historia reciente de los países involucrados. En el caso de Perú, la movilidad internacional se ubica entre las corrientes de peruanos al exterior, ocurrida desde los años 80 a la fecha. Los destinos migratorios extrarregionales predilectos de los peruanos han sido, entre otros, Estado Unidos y Europa; y recientemente Chile como destino intrarregional, ocupando el cuarto lugar de preferencia ${ }^{8}$. En el plano internacional, las razones que han impulsado a los peruanos a

8 En el periodo 1995-2005 se estima que 1.665.850 peruanos migraron al exterior. Entre los destinos más importantes se ubican Estados Unidos con 514.491 personas, le sigue España con 238.990 personas, Ar- emigrar a Chile se vinculan con las restricciones impuestas por los países de mayor desarrollo a través de la imposición del visado, en el caso de España (1999), el endurecimiento de la entrada a Estados Unidos después del 11-S y las crisis institucionales ocurridas en las últimas décadas, entre ellas se consigna la llegada a Santiago de los primeros refugiados políticos producto de la crisis constitucional de 1992 bajo el mandato de Alberto Fujimori (1990-2000) (Luque, 2007). A ello se suma la inestabilidad económica por la que atravesó Perú en esos años y el impacto social que produjo la aplicación de políticas neoliberales durante el mismo periodo (Altamirano, 1992). En este contexto la cercanía geográfica de Chile y Perú ha favorecido la elección de nuestro país como el destino migratorio más reciente (Navarrete, 2007).

En el caso de Bolivia, los estudios señalan que el destino migratorio intrarregional preferente ha sido Argentina (Benencia, 2005; Ceva, 2006). Desde mediados del siglo XIX existen registros censales que advierten de una proporción cercana al 20\% de población de origen fronterizo en Argentina sobre el total de extranjeros de ese país. Sin embargo, el peso de los migrantes limítrofes ha variado a lo largo del siglo XX, en 1914 solo representaban el $8 \%$ del total de inmigrantes y para el año 1991 esa proporción superaba el 50\% (Ceva, 2006: 4). Claro está que durante la época de oro de la inmigración transatlántica, el peso de los inmigrantes de origen fronterizo se tendió a diluir, y a la inversa, desde que se detuvo el flujo europeo la proporción de migrantes fronterizos tendió a aumentar. Hacia fines del siglo XIX y principios del XX la migración internacional se convirtió en un elemento clave para el desarrollo económico y social de Argentina ${ }^{9}$. Sin embargo, a me-

gentina con 210.642 personas y Chile con 174.416 , según fuentes peruanas (INEI, 2006: 26).

9 Se estima que entre 1871 y 1914 entraron más de cinco millones de extranjeros a Argentina, de los cuales un poco más de tres millones se radicaron definitivamente y el resto regresó a Europa. La mayoría de los inmigrantes provino de España e Italia y se radicaron básicamente en la zona del litoral pampeano, lo que produjo un incremento sustantivo de la población de ciudades como Capital Federal, Buenos Aires, Santa Fe, Córdoba y Entre Ríos (Gallo, 1992: 45). 
dida que transcurría el siglo XX la población boliviana avanzó progresivamente desde la frontera boliviano-argentina hasta el Área Metropolitana de Buenos Aires en movimientos circulares o de idas y venidas (Hinojosa, 2000), y de establecimiento hacia fines del siglo XX (Benencia, 2004, 2005; Ceva, 2006). En este contexto, Chile, hasta hace poco, no había sido el destino preferente de la emigración boliviana, sin embargo, el arribo de dicha población al norte del país se relaciona con la atracción que ejerce la actividad comercial impulsada por la creación de la ZOFRI, la necesidad de cubrir mano de obra agrícola -por la migración campo-ciudad de los campesinos del interior de la región- y por las diferencias salariales que se registran a uno y otro lado de la frontera, lo que motiva la búsqueda de trabajos temporales o permanentes en la región (Rodríguez, 2005). Por tanto se reconoce que más que un fenómeno nuevo se trata de la visibilización de la migración limítrofe y de prácticas fronterizas que poseen una profundidad histórica de carácter regional.

En la actualidad es posible afirmar que la preocupación por la migración de peruanos a la capital chilena ha puesto en el tapete la preocupación por los límites de manera similar a lo ocurrido en otras latitudes, como fue el caso de la migración boliviana al Área Metropolitana de Buenos Aires a fines del siglo XX o recientemente el desplazamiento de colombianos hacia la frontera ecuatoriana. Los datos recientes señalan que actualmente dos millones de personas componen los movimientos de población intrarregional en América Latina $\left(\right.$ Nicolao, 2011) ${ }^{10}$. En este contexto, las estimaciones del Departamento de Extranjería y Migración del Ministerio del Interior de Chile señalan que para el año

\footnotetext{
10 Dentro del patrón migratorio intrarregional se identifican dos subsistemas que han predominado durante el siglo XX y principios del siglo XXI. Se trata, por un lado, del Cono Sur que tiene como destino migratorio a Argentina y, por otro lado, del subsistema andino que tiene como destino Venezuela (Canales, et al., 2010; A Solimano, 2003). Ambos países mantienen su supremacía como plaza de la migración sudamericana e incluso del Caribe. Para el año 2010, residían 1,4 millones de migrantes en Venezuela y un millón de inmigrantes en Argentina (Nicolao, 2011)
}

2009 había 352.344 extranjeros, de los cuales un $37,1 \%$ correspondía a peruanos y un $17,2 \%$ a bolivianos (Ministerio del Interior, 2010).

A nivel nacional, los datos del censo 2002 informan que los extranjeros que residen en Chile provienen principalmente de Argentina, Bolivia, Ecuador y Perú (el 58\% del total de extranjeros). Argentina es el país de origen el más importante con el $26 \%$, le siguen Perú $(21 \%)$, Bolivia $(6 \%)$ y finalmente Ecuador (5\%) (Martínez, 2003). Para el caso de la Región de Tarapacá, el censo en estudio señala que los extranjeros residentes en la región alcanzaron un total de 12.746 personas, lo que representa un $3 \%$ de la población total regional (428.594). Aunque se trata de una proporción baja en relación a la población nacional, es necesario advertir que este valor casi triplica a la proporción nacional de extranjeros $(1,2 \%)$. De esta forma, Tarapacá ocupa el primer lugar en términos relativos de población extranjera respecto del total de la población regional y se ubica, a su vez, en el tercer lugar entre las regiones con mayor contingente de población extranjera.

En relación a lo anterior, la bibliografía reciente Ilama la atención por el aumento que experimentaron los extranjeros de origen peruano en los últimos censos. Los datos censales advierten que el $42 \%$ de los inmigrantes que Ilegaron a Chile entre 1992 y 2002 vinieron desde Perú, colectivo que casi cuadriplicó (395\%) su crecimiento, pasando de 7.649 personas a 37.863 , en este periodo intercensal (Solimano y Allendes, 2008: 205). Este crecimiento es el que ha suscitado el interés de la investigación social y ha levantado la voz de alarma desde los medios de comunicación.

Asimismo, se destaca el cambio en la dirección de la migración peruana en el país que por largo tiempo había permanecido en las regiones del extremo norte como un fenómeno propio de los márgenes. De modo que la llegada a la capital chilena de los extranjeros limítrofes, el tipo de asentamiento en la capital -en el centro de la ciudad y en los barrios acomodados con las "nanas peruanas"- y la ocupación de espacios céntricos capitalinos (Schiappacasse, 2008), son aspectos que han suscitado el interés por la mi- 
Figura $\mathrm{N}^{0} 1$

Crecimiento de la población extranjera fronteriza en la Región de Tarapacá, 1982-1992

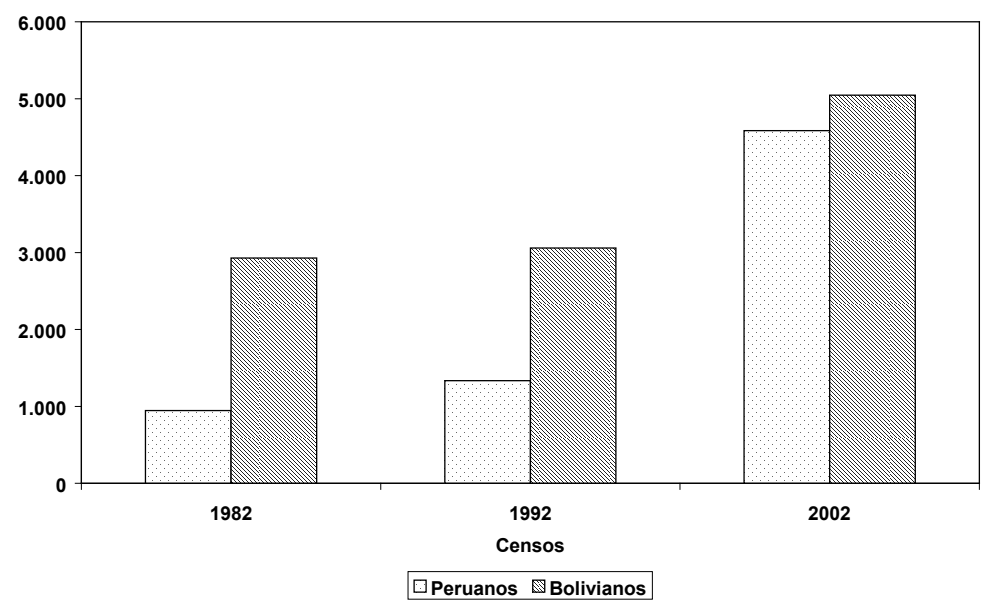

Fuente: Elaboración propia en base a datos de INE.

gración fronteriza ${ }^{11}$. Sin embargo, no se trata solo de la visibilización de los extranjeros en la capital, sino de la preocupación de la periferia como centro, de acuerdo al cual el interés por la frontera y la movilidad humana se ha convertido en un foco de atención. La migración limítrofe, propia de los márgenes, que hoy llega al centro del país, ha reavivado el carácter protector y separador de la frontera y la atención por los márgenes ${ }^{12}$.

\section{Algunos rasgos estilizados en el análisis de los censos de 1982, 1992 y 2002}

a) Cambios en el destino de las migraciones fronterizas

Al revisar las tres últimas rondas censales para la Región de Tarapacá, se aprecia un aumento general entre los extranjeros provenientes de Perú y Bolivia con algunas distinciones. Los peruanos experimentaron un crecimiento mayor respecto de los bolivianos

\footnotetext{
11 Solo el 2\% de la población de la Región Metropolitana es extranjera (Schiappacasse, 2008).

12 En octubre de 2011, el Gobierno de Chile lanzó el Plan Frontera Norte cuyo objeto es evitar el ingreso y salida de droga por el mar y pasos fronterizos del extremo norte chileno (Ministerio de Defensa Nacional, 4 de octubre 2011).
}

en la región. Según los datos de 2002, los peruanos aumentaron en un $79 \%$ respecto del año 1982 y los bolivianos un 42\% respecto al mismo año. Es decir, de 946 peruanos en 1982 se pasó a 4.584; y de 2.929 bolivianos a 5.045. En total, casi 6.000 extranjeros más en la región para el periodo señalado. Aunque la tendencia que se verifica en la región es coincidente con lo que ocurre a nivel nacional, los valores absolutos están muy lejanos a los alcanzados a nivel nacional, donde la Región Metropolitana concentra actualmente la mayor cantidad de extranjeros de origen fronterizo, especialmente peruanos.

A nivel nacional, entre los años censales de 1982 y 2002 Ilegaron 100 mil nuevos inmigrantes al país, de los cuales casi la mitad son de origen sudamericano, especialmente peruanos y argentinos. En este sentido lo que se registra a nivel nacional es "una suramericanización de los inmigrantes en Chile" (Solimano y Tokman, 2008: 205), puesto que en las últimas rondas de censos los europeos pierden importancia relativa y absoluta.

Al revisar el conjunto de los datos en perspectiva histórica, se observa que a partir de la crisis del salitre el colectivo peruano registró un aumento lento pero progresivo en Santiago. A pesar de que las cifras absolutas 
Figura $\mathrm{N}^{\circ} 2$

Distribución de los extranjeros de origen fronterizo por regiones, 1992 y 2002

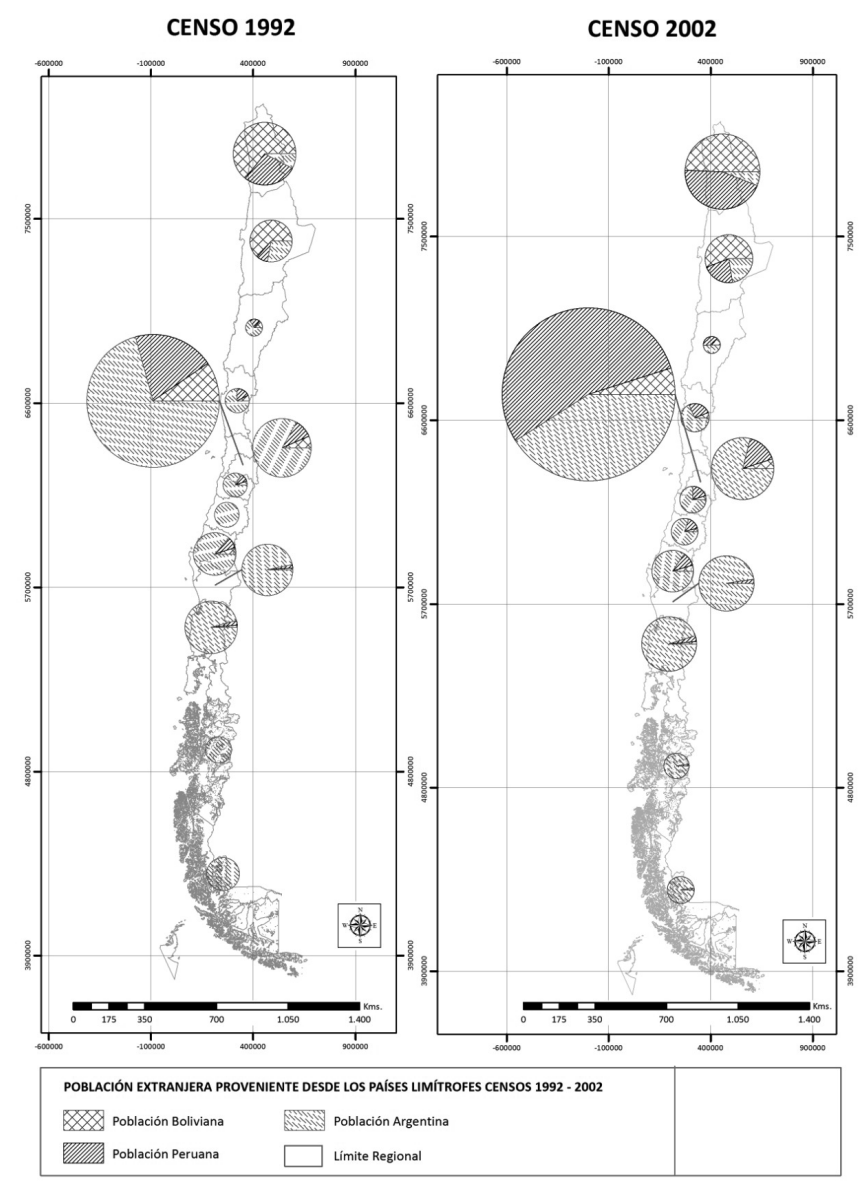

Fuente: Elaborado por el Instituto de Estudios Internacionales (INTE), Universidad Arturo Prat y el Sistema Nacional de Coordinación de Información Territorial (SNIT), Gobierno Regional de Tarapacá.

son bajas, se aprecia que para el año 1940 de un total nacional de 3.893 peruanos, el 38\% del total se encontraba en la capital. Aunque en 1960 los valores absolutos siguen bajando de un total nacional de 1.969 personas de ese país, casi la mitad se encontraba en Santiago. En la década de los setenta y los ochenta, en un contexto de régimen militar y crisis económica, las fronteras chilenas se mantuvieron cerradas bajo la lógica de la seguridad interior del Estado, lo que explica la caída en los valores absolutos de peruanos y bolivianos en Chile, Ilegando en 1982 a 6.112 bolivianos y 4.101 peruanos a nivel nacional (INE). Es a partir de 1980 que la migración fronteriza retoma un nuevo impulso, especialmente hacia la capital chilena, y hacia los noventa se consolida con el retorno a la democracia, el afianzamiento económico y un ritmo constante de crecimiento (Araujo et al., 2002; Stefoni, 2003). En definitiva, existe coincidencia en aceptar que el punto de inflexión se produce en los 90, que es cuando se origina el mayor crecimiento intercensal de peruanos a nivel nacional y cuando se evidencia su concentración en la Región Metropolitana como se aprecia en el Figura $N^{\circ} 2$.

Al devolvernos a las cifras de las últimas rondas censales y observar lo que ocurre en la Región de Tarapacá, se aprecia que el crecimiento de los extranjeros de origen peruano y boliviano está por debajo del aumento que experimentaron los mismos colectivos a nivel nacional. En este sentido, la mayor concentración de extranjeros fronterizos ya no se 
Figura $\mathrm{N}^{\circ} 3$

Extranjeros de origen peruano y boliviano en Tarapacá según censo, 1907-2002

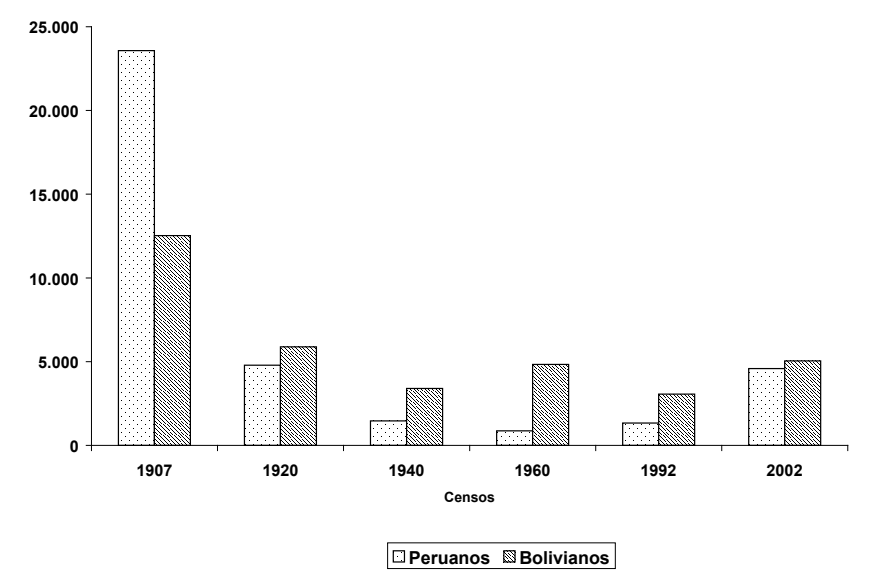

Fuente: Elaboración propia en base a INE.

concentra en Tarapacá, como señalaban los censos de principios del siglo XIX, sino que se han desplazado hacia el centro del país. Las razones del desplazamiento de la región fronteriza por la Región Metropolitana -especialmente de peruanos- se relacionan con distintos factores. Uno de ellos es que los primeros migrantes que arribaron a Santiago fueron refugiados políticos luego de la llegada de Fujimori al poder en 1992 (Luque, 2007). Luego, le siguieron los migrantes económicos peruanos que llegaron atraídos por las mayores oportunidades de trabajo en nichos laborales específicos y cambios en el marco legal que terminaron con las trabas para el ingreso al país ${ }^{13}$. Asimismo, la crisis económica peruana de los años 90, las bajas expectativas de mejoría en el corto plazo y la cercanía con Chile ha motivado la elección de nuestro país como destino migratorio fronterizo.

\footnotetext{
13 La Ley 19.273 de 1993 derogó las disposiciones de entradas y salidas a los residentes en territorio chileno. La Ley 19.581 de 1998, que creó una categoría de ingreso para habitantes de zonas fronterizas, y el Decreto Supremo 3.553 que introdujo modificaciones relativas a la residencia definitiva y a los trámites en Extranjería, y el Decreto 2.910 que permite a los extranjeros obtener permiso de trabajo mientras se tramita la residencia temporal en Chile (CEOC, 2005; Navarrete, 2007).
}

En síntesis, la presencia de peruanos en Tarapacá ha pasado de ser mayoritaria a principios del siglo $X X$, para decaer desde la década de 1930 y ser superado por el colectivo boliviano durante casi toda la centuria pasada. De hecho, en el último censo de 2002 los extranjeros residentes provenientes de Bolivia alcanzaron un total de 5.045 personas y los peruanos un total de 4.584 personas, constituyéndose los bolivianos en el primer colectivo extranjero de importancia en la región según el censo de 2002. En general, la tendencia que se observa es la preferencia de los migrantes fronterizos por los centros urbanos de alta concentración donde las posibilidades laborales aumentan y la existencia de redes migratorias favorece el establecimiento. Sin embargo, en la zona fronteriza no desaparece la presencia extranjera sino que permanece $y$ da lugar a formas distintas de movilidad entre ellas la circularidad, el tránsito de comerciantes y el establecimiento (Arriaza, 2007; Berganza y Cerna, 2011; Llanque, 2011; Rodríguez, 2005). Estudios recientes advierten de las ventajas que ofrecen ciudades como Arica e Iquique para peruanos y bolivianos, gracias a cambios en el marco jurídico que propicia la circulación-Convenio Tacna y Arica y MERCOSUR- y las oportunidades económicas y salariales que ofrece el cruce de la frontera (Berganza y Cerna, 2011). Estos movimientos de población, regularmente no son captados por los censos, por lo cual es nece- 
Figura $\mathrm{N}^{\circ} 4$

Extranjeros de origen fronterizo en Tarapacá, por sexo durante el siglo XX y XXI

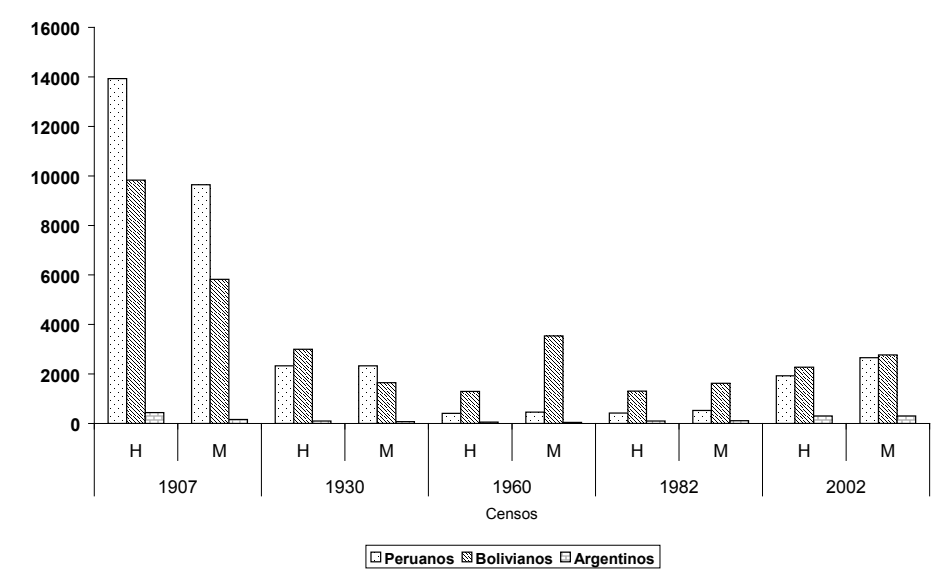

Fuente: Elaboración propia en base a INE, Censo de Población y Vivienda.

Cuadro $\mathrm{N}^{\circ} 2$

Índice de masculinidad de extranjeros de origen fronterizo

\begin{tabular}{|l|l|l|l|l|l|}
\hline & 1907 & 1930 & 1960 & 1982 & 2002 \\
\hline Peruanos & 144,4 & 99,9 & 90,1 & 80,2 & 72,5 \\
\hline Bolivianos & 168,8 & 181,7 & 36,7 & 80,4 & 82,1 \\
\hline Argentinos & 271,0 & 127,3 & 138,1 & 89,3 & 98,7 \\
\hline
\end{tabular}

Fuente: Elaboración propia en base a INE, Censos de Población y Vivienda.

sario recurrir a fuentes alternativas que permitan mensurar el fenómeno para caracterizarlo y comprenderlo ${ }^{14}$ (Figura $\mathrm{N}^{\circ} 3$ ).

b) De la masculinización a la feminización de la migración fronteriza

En relación a los rasgos sociodemográficos de los colectivos fronterizos presentes en la región, es posible observar que durante el ciclo salitrero se registró mayor presencia de hombres que de mujeres de origen limítrofe. Se trató en su mayoría de varones jóvenes en

\footnotetext{
14 La autora se encuentra ejecutando el proyecto FONDECYT de Iniciación 11110096 titulado Frontera, migración y movilidad humana fronteriza en la Región de Tarapacá 1990-2007, que investiga los temas señalados.
}

edad productiva (Figura $N^{\circ} 4$ ). Según el censo de 1885, los colectivos peruano y boliviano correspondían a población soltera y dedicada a ocupaciones como gañanes, mineros, agricultores, jornaleros, sirvientes y costureras. Para el mismo censo, las ocupaciones de mayor demanda en el caso peruano, eran el de agricultor, sirviente, gañán, comerciante y lavanderas (Norambuena, 2002).

Desde mediados del siglo XX se registra un aumento de las mujeres extranjeras de origen fronterizo, tendencia que es notoria en el caso del colectivo boliviano a partir de los años 1960 y 1982. Aunque esta tendencia se acentúa desde la segunda mitad del siglo $X X$, en el último censo tienden a equipararse hombres y mujeres de origen fronterizo con un predominio de estas últimas. Con todo, es posible apreciar que en Tarapacá se ha pasa- 
do de una notoria masculinización de los extranjeros de origen fronterizo a principios del siglo XX, a una incipiente feminización de los extranjeros establecidos en la región durante el siglo XXI.

A nivel nacional, la bibliografía ha llamado la atención acerca del aumento de las mujeres en los flujos migratorios, especialmente en el censo de 2002 de acuerdo al cual, del total de extranjeros, el 52\% correspondió a mujeres (Martínez, 2003). El Cuadro No2 muestra que entre los colectivos extranjeros con mayor proporción de mujeres destaca Perú con un índice de masculinidad de 0,66, lo cual sitúa a este grupo a la cabeza en presencia femenina (Solimano y Tokman, 2008: 214). Los factores que explican esta tendencia se vinculan a las oportunidades laborales encontradas en la capital chilena especialmente en el ámbito de los Ilamados servicios de proximidad o servicios de la vida diaria, es decir, "aquellas actividades remuneradas destinadas a satisfacer las necesidades de las personas y de las familias que surgen del desarrollo de la vida cotidiana" (Parella, 2005: 98). Por ejemplo, las mujeres peruanas han ocupado un nicho laboral específico en el servicio doméstico que ha venido a satisfacer la demanda de mano de la capital chilena (Araujo et al., 2002; Stefoni, 2009).
Los cambios en la composición de los flujos migratorios, de masculinizado a feminizado, tiene estrecha relación con los ciclos económicos nortinos y el efecto llamada que ha tenido el mercado laboral en cada momento de la historia regional. En el pasado, la industria salitrera demandó preferentemente mano de obra masculina para la explotación del nitrato especialmente en el proceso de extracción, explotación y transporte. Más tarde con la crisis del salitre se registró una caída en la presencia de extranjeros fronterizos en la región, mas no su desaparición, como se ha apuntado. En las últimas décadas se ha experimentado un auge de la actividad comercial a través de la creación de la Zona Franca de Iquique (1975). A partir de los 90 el dinamismo económico ha venido de la mano de la actividad cuprífera que ha demandado mano de obra para la actividad minera e impulsado otros sectores de la economía como la construcción y los servicios. De acuerdo a un estudio basado en los datos recolectados por la Pastoral Migratoria de Iquique, las mujeres bolivianas y peruanas tienden a ubicarse en la economía informal en el servicio doméstico y en el pequeño comercio (Arriaza, 2007). En tanto, los varones de los mismos colectivos se insertan fundamentalmente en la construcción, el comercio y la agricultura (Rodríguez, 2005). Por tanto, los extranjeros de origen fronterizo vienen

Figura $\mathrm{N}^{\circ} 5$

Años de formación de peruanos residentes en Tarapacá según censos, 1982, 1992 y 2002

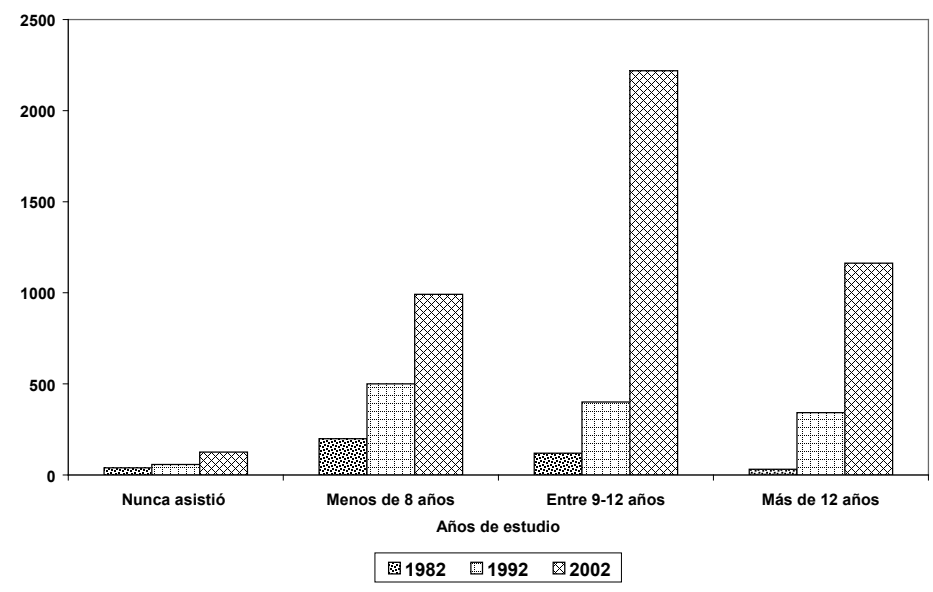

Fuente: Elaboración propia en base a INE, Censos de Población y Vivienda. 


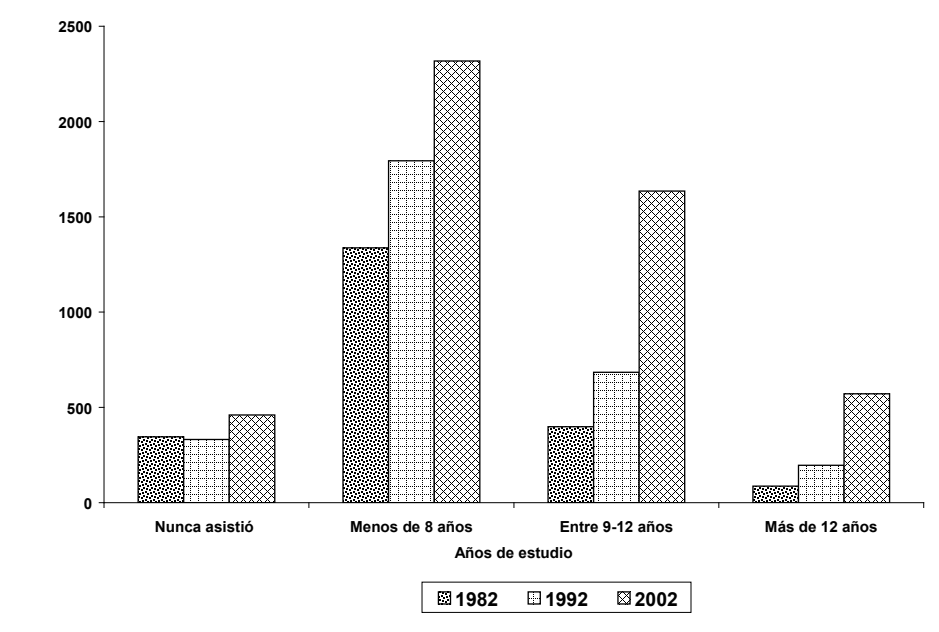

Fuente: Elaboración propia en base a INE, Censos de Población y Vivienda.

a ocupar nichos laborales en trabajos riesgosos y pesados en el caso de los varones o devaluados socialmente como es el caso del servicio doméstico.

Este fenómeno no se da descontextualizado con lo que ocurre en otras latitudes, sino que se trata de una tendencia mundial dada por el envejecimiento de las sociedades de los países desarrollados y en vías de desarrollo, el aumento de las mujeres nacionales en el mercado de trabajo y la tendencia a permanecer en él, la disminución del tamaño de las familias y el surgimiento de distintas formas familiares, entre los factores más destacables (Comisión Europea, 2004). De modo que cada vez más mujeres deciden migrar para trabajar en servicios de cuidados y tareas domésticas, aunque en muchas ocasiones estén sobrecalificadas para hacerlo (Navarrete, 2007; Stefoni, 2009). La motivación principal es fundamentalmente económica, lo que se configura como una estrategia familiar temporal para buscar mejores condiciones aprovechando las diferencias salariales que se producen al cruzar las fronteras.

\section{c) Escolaridad y asentamiento geográfico}

Respecto a los años de escolarización de los colectivos peruanos y boliviano en Tarapacá, según las tres últimas rondas de censos, se aprecia que en general ambos grupos tienden a aumentar los años de estudio durante el periodo censal estudiado (Ver Figura $N^{\circ}$ 5). Sin embargo, se evidencian diferencias entre los dos grupos, los peruanos experimentan un crecimiento sostenido en el tramo de los 12 años de escolarización, es decir, enseñanza secundaria completa; y de más de 12 años, que corresponde a enseñanza técnico profesional $y / o$ universitaria. En ambos casos se experimentó un crecimiento de 18 y 37 veces en los respectivos subgrupos de escolarización (entre 9-12 años y más de 12 años) para el periodo intercensal de 1982 a 2002.

En el caso de los bolivianos asentados en Tarapacá, se aprecia que este grupo se concentra en el tramo de menos de 12 años de escolarización y tiende a mantenerse en él durante el periodo intercensal estudiado. Sin embargo, se advierte que en el grupo de 9 a 12 años de estudios experimenta un crecimiento de 6,5 veces desde 1982 al año 2002 (Figura $\mathrm{N}^{\circ} 6$ ).

En relación a la distribución de los extranjeros de origen fronterizo en la antigua Región de Tarapacá, se aprecia en la Figura $N^{\circ}$ 7 un aumento en el tiempo y una distribución desigual en la región. Los bolivianos tienden a concentrarse en las provincias de Arica y 
Figura $\mathrm{N}^{0} 7$

Distribución de la población extrajera de origen fronterizo en la Región de Tarapacá

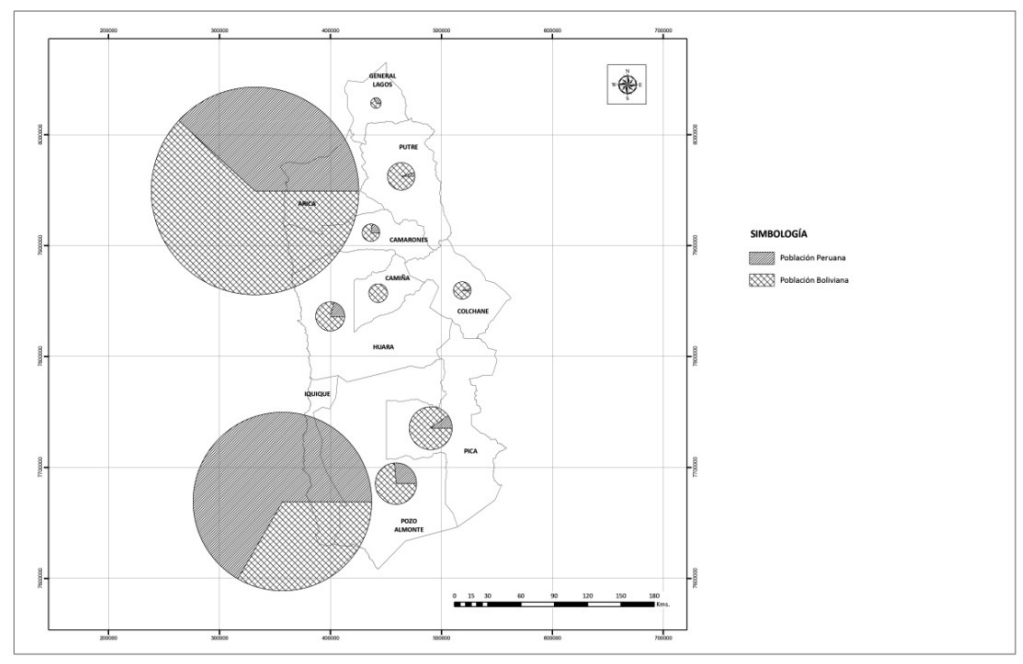

Fuente: Elaborado por el Instituto de Estudios Internacionales (INTE) de la Universidad Arturo Prat y el Sistema Nacional de Coordinación de Información Territorial (SNIT), Gobierno Regional de Tarapacá

los peruanos en la provincia de Iquique en las tres últimas rondas de censos. Al revisar por comunas de acuerdo al censo de 2002, se advierte una mayor concentración urbana de ambos colectivo, los bolivianos preferentemente en la comuna de Arica y los peruanos en la comuna de Iquique.

El enfoque diacrónico del análisis de los censos permite dimensionar los cambios en los flujos migratorios y los rasgos que adquieren en cada momento. A partir de la constatación de la importancia que han tenido los extranjeros de origen limítrofe en la Región de Tarapacá a lo largo de la historia, se han distinguido dos momentos centrales con rasgos propios y a la vez opuestos. El primero se ubica luego del fin del conflicto bélico de 1879 y la incorporación de los territorios nortinos que coincide a su vez con la expansión del ciclo salitrero. El segundo remite a los años 90 del siglo XX en el marco del aumento de la inmigración fronteriza a Chile y la tendencia a la suramericanización de su composición. En el primer caso, los colectivos estudiados, bolivianos y peruanos, se concentraron fundamentalmente en Tarapacá con una mayor presencia masculina. La actividad del nitrato produjo un efecto llamada, no solo a los extranjeros internacionales y fronterizos, sino también de los nacionales que poblaron la región dando lugar a la sociedad pampina. Sin embargo, el segundo momento dice relación con razones distintas a la primera, de acuerdo a la cual la migración fronteriza se ubica en el marco del contexto crisis social y política de los países emisores y de las restricciones impuestas a la migración de larga distancia en los países desarrollados. En ese contexto, Chile se vislumbra como uno de países de mayor estabilidad de la región donde la cercanía geográfica, las facilidades para el ingreso y las diferencias salariales actúan como los principales incentivos para elegir al país como nuevo destino migratorio (Solimano y Tokman, 2008).

En este nuevo escenario el protagonismo del fenómeno migratorio ya no es solo regional -aunque no desaparece-, sino especialmente metropolitano. Perú y Bolivia poseen una historia reciente de expulsión de población que las sitúa entre los países de América Latina con más contingentes nacionales viviendo fuera de sus fronteras (Altamirano, 1992; Hinojosa, 2006). La ins- 
cripción de Chile en este proceso es parte de una imbricación de factores que han propendido a su elección como uno de los destinos preferentes. Como señalamos más arriba, el aumento de la demanda por mano de obra en nichos específicos de trabajo para extranjeros, las modificaciones en el marco jurídico sobre extranjería y las diferencias salariales, han favorecido el cambio de destino migratorio desde el extremo norte a la Región Metropolitana. La reciente demanda laboral migrante se asemeja a las sociedades modernas caracterizada por la disminución de la aceptabilidad laboral de ciertos oficios -casi siempre devaluados socialmente o pesados y riesgosos- por parte de los nacionales, para ser ocupados por los extranjeros. Este cambio es acorde con fenómenos similares en América Latina en los que se experimenta una creciente preferencia de los migrantes internos y fronterizos por las ciudades de mayor jerarquía. Sin embargo, los cambios en la dirección de los flujos y la centralidad que adquiere en la Región Metropolitana -de acuerdo a los censos estudiados-, no supone una pérdida de relevancia de los fronterizos en el extremo norte, sino que está dando lugar nuevas prácticas migratorias y de movilidad de carácter transfronterizo.

Queda por esperar los resultados del Censo de Población y Vivienda 2012, el que nos permitirá establecer con mayor claridad las tendencias señaladas y la confirmación o no de la configuración de Chile como país receptor de migrantes fronterizos.

\section{Conclusiones}

El análisis que vincula frontera y migración amplía la comprensión de los movimientos de población y al mismo tiempo plantea nuevos desafíos teóricos y metodológicos; asimismo, la inclusión de la diacronía en el análisis permite poner en perspectiva temporal y geográfica los desplazamientos de la población extranjera y sus especificidades. Una vez hecho el análisis se advierte que desde la escala nacional, por largo tiempo, predominó la noción de espacio fronterizo como un lugar donde todo se acaba, lejano, inhóspito y anecúmene. Esta visión dio por resultado el desconocimiento o escaso interés investigativo por explorar los movimientos de población limítrofes -más allá de los estudios históricos- y la simplificación de la frontera a la definición geográfica y política.

El trabajo realizado demuestra que el fenómeno migratorio siempre ha existido a nivel regional, hecho que ha puesto en evidencia las consecuencias sociales que tiene la contigüidad fronteriza a lo largo de la historia. Sin embargo, una vez que el fenómeno se desplaza de la frontera al centro del país, adquiere un nuevo significado y se define como novedoso. Queda en evidencia, por una parte, la superposición de las escalas -nacional y regional-y el predominio de la jerarquía en el análisis; y por otra, instala en el debate el desafío de incluir la escala global para comprender el segundo momento de mayor de inmigración fronteriza de instalación metropolitana. En distintas latitudes cada vez es más claro que las migraciones fronterizas e internacionales se dirigen a los grandes centros urbanos, del norte y del sur, donde aumentan las oportunidades laborales gracias a las conexiones de las urbes con los distintos circuitos globales.

La explotación del nitrato atrajo a miles de trabajadores de Chile y del mundo dando lugar a una sociedad pampina y a la inserción del país en la economía internacional. Sin embargo, el fin del ciclo y la crisis produjo un proceso de retorno a las localidades de origen y a migración interna. La consolidación económica de las últimas décadas y las transformaciones sociales que ha experimentado la sociedad chilena, ha favorecido la llegada de extranjeros fronterizos dispuestos a ocupar nichos laborales específicos. Este nuevo escenario ha redireccionado los flujos migratorios de la zona fronteriza al centro del país, sin por ello perder importancia en el extremo norte. En ambos casos la motivación del desplazamiento ha sido fundamentalmente económica, por tanto el desafío es hacer una nueva lectura de los distintos momentos para dilucidar cómo lo global se inscribe en lo regional y nacional y cómo la frontera se pone en el centro del debate.

Desde el punto de vista de las fuentes de información estadística, el estudio de las migraciones basada en el análisis y explotación de los censos de población, sigue siendo el punto de partida de cualquier investigación 
que pretenda conocer el panorama migratorio, en este caso, de una región extrema. Queda pendiente ampliar este estudio a los resultados del Censo 2012 y la confirmación o no de Chile como país de destino migratorio latinoamericano.

Sin embargo, se constata que la definición de migración internacional es insuficiente para comprender los fenómenos que ocurren en los espacios fronterizos al quedar estos enmarcado en los límites de lo nacional. De modo que la consideración de los espacios fronterizos para el estudio de las migraciones se constituye en una unidad de análisis que permite relativizar la importancia de las escala en los estudios migratorios. Si bien es indiscutible el valor de los censos de población para la cuantificación de los movimientos de población estos remiten regularmente al ámbito de lo nacional, hecho que en ocasiones tiende a simplificar los fenómenos que ocurren en los espacios contiguos. Por tanto, se evidencia la necesidad de ampliar las fuentes que nos informan sobre la realidad migratoria que permitan captar la variedad de formas que adquiere la movilidad humana, entre ellas la circularidad migratoria de los trabajadores agrícolas bolivianos o los desplazamientos de chilenos que diariamente cruzan la frontera de Chacalluta-Santa Rosa por motivos comerciales o médicos.

En relación a los censos, surge el desafío de explorar nuevas las formas de cuantificar los desplazamientos humanos con el objeto de superar las definiciones que privilegian la residencia para así reconocer la variedad de formas que adquiere la movilidad humana en el espacio fronterizo. Avanzar hacia la tipificación de las distintas formas de movilidad fronteriza predominantes en la región permitirá superar las nociones fijas de la residencia y el establecimiento que otorgan las fuentes. Asimismo, permitirá dilucidar la definición que los habitantes fronterizos hacen de la frontera y las redefiniciones que elaboran de ella al cruzarla.

De acuerdo al análisis realizado quedan preguntas e hipótesis de investigación abiertas para futuras investigaciones. La primera referida a dilucidar el papel que juega la Región de Tarapacá en este contexto, es decir, si de región de destino migratorio, como ocurrió en el pasado, ha pasado a constituirse en una región de tránsito desde la cual se configuran proyectos migratorios que tienen como objetivo último Santiago. O la segunda hipótesis postula que los movimientos de población en el espacio fronterizo tarapaqueño son independientes de los flujos que tienen como destino la capital chilena y están más afectadas por la internacionalidad del espacio fronterizo y las oportunidades que se encuentran a la hora de cruzar la frontera en uno y otro sentido. Es probable que ambos fenómenos se desarrollen de manera paralela y que las diferencias se vinculen a la acción de las redes migratorias y a los orígenes regionales de los colectivos estudiados, exploración que permitiría avanzar en la tipificación de las dinámicas migratorias actuales.

\section{Referencias bibliográficas}

AGUILERA, R. La anexión del territorio de Tarapacá a Chile y sus efectos en la realidad andina de los valles tarapaqueños (1880 a 1922). En: GÁLVEZ, M.; RUZ, R. y DíAZ, A. (Editores). Tarapacá un desierto de historias. Historia, cultura y memoria en el norte chileno S. XIX y XX. Iquique: FONDART Regional Tarapacá, 2003, p. 21-36

AltamiRanO, T. Éxodo: Peruanos en el exterior. Lima: Pontificia Universidad Católica, 1992.

ARANGO, J. Las migraciones internacionales en un mundo globalizado. Vanguardia Dossier, 2007, № 22, p. 8-15.

ARAUJO, K.; LEGUA, C. y OSSANDÓN, L. Migrantes andinas en Chile. El caso de la migración peruana. Santiago de Chile: Fundación Instituto de la Mujer, 2002.

ARRIAZA, P. Claves de la integración social de los inmigramtes extranjeros: el caso de los inmigrantes peruanas(os) y bolivianas(os) participantes en la Pastoral de Migración de la ciudad de Iquique. Iquique: Fondo de Solidaridad e Inversión Social (FOSIS), 2007.

BARTOLOMÉ, A. Fronteras estatales y fronteras étnicas en América Latina. Notas sobre el espacio, la temporalidad y el pensamiento de la diferencia. En: VELASCO, L.C. 
(Editor). Migración, fronteras e identidades étnicas transnacionales. México: Miguel Ángel Porrúa/COLEF, 2008, p. 35-77.

BECK, U. ¿Qué es la globalización? Falacias del globalismo, respuestas a la globalización. Barcelona: Paidós, 2008.

BENENCIA, R. Familias bolivianas en la producción hortícola de la provincia de Buenos Aires. Proceso de diseminación en un territorio transnacional. En: HINOJOSA, A. (Editor). Migraciones Transnacionales. Visiones de norte y Sudamérica. La Paz: CEF/Editorial Plural, 2004.

BENENCIA, R. Migración limítrofe y mercado de trabajo rural en la Argentina. Estrategias de familias bolivianas en la conformación de comunidades transnacionales. Revista Latinoamericana de Estudios del Trabajo, 2005, Vol. 10, No 17, p. 5-30.

BERGANZA, I. y CERNA, M. Dinámicas migratorias en la frontera Perú-Chile. Arica, Tacna e Iquique. Lima: Departamento Pastoral de Movilidad Humana, 2011 (Inédito).

CALLE, M. Peruanos, bolivianos y argentinos en Tarapacá según sua pautas matrimoniales: ¿Pluralismo cultural o crisol de razas? 1885-1910. Revista de Ciencias Sociales, 2008, N²1, p. 29-59.

CANALES, A.; MARTÍNEZ, J.; REBOIRAS, L. y RIVERA, F. Migración y salud en zonas fronterizas: Informe comparativo sobre cinco fronteras seleccionadas. Santiago de Chile: CEPAL, 2010.

CANO, M. V. y SOFIA, M. Los estudios sobre migración internacional en Chile: apuntes y comentarios para una agenda de investigación actualizada. Papeles de Población, 2009, Vol. 15, Nº1, p. 129-167.

CASTRO, L. Minería de altura de Antofagasta y la inmigración boliviana e indígenea en el norte de Chile (Tarapacá 1880-1930). Si SomosAmericanos. Revista de Estudios Transfronterizos, 2010, Vol. X, No 2, p. 129-145.

CENTRO DE ESTUDIOS DE OPINIÓN CIUDADANA (CEOC). Situación de los pe- ruanos en Chile. Talca: Centro de Estudios de Opinión Ciudadana CEOC, 2005.

COMISIÓN CENTRAL DEL CENSO. Memoria presentada al Supremo Gobierno por la Comisión Central del Censo. Santiago de Chile: Comisión Central del Censo, 1907.

COMISIÓN ECONÓMICA PARA AMÉRICA LATINA Y EL CARIBE/CENTRO LATINOAMERICANO DE DEMOGRAFÍA (CEPAL/ CELADE). Cuatro temas centrales en torno a la migración internacional, derechos humanos y desarrollo. Santiago de Chile: CEPAL, 2006.

CEVA, M. La migración limítrofe hacia la Argentina en la larga duración. En: GRIMSON, A. y JELIN, E.C. (Editores). Migraciones regionales hacia la Argentina: diferencia, desigualdad y derechos. Buenos Aires: Prometeo Libros, 2006, p. 17-46.

COMISIÓN EUROPEA. Hogares, cuidados y fronteras...derechos de las mujeres inmigrantes y conciliación. Madrid: Traficantes de sueños, 2004.

DIRECCIÓN GENERAL DE ESTADÍSTICA. Censo de la población de la República de Chile. Santiago de Chile: Sociedad Imprenta. y Litografía Universo, 1920.

DIRECCIÓN GENERAL DE ESTADÍSTICA. Resultados del X Censo de la población. Santiago de Chile: Imprenta Universo, 1930.

GALLO, E. Política y sociedad en Argentina 1870-1916. En: BETHELL, L.E. (Editora). Historia de América Latina. América del Sur, 1870-1930. Barcelona: Cambridge University Press/Editorial Crítica, 1992, p. 41-66.

GARDUÑO, E. Antropología de las fronteras, la migración y los procesos transnacionales. Frontera Norte, 2002, Vol. 15, № 30, p. 65-89.

GAVILÁN, V. y TAPIA, M. Diagnóstico de los procesos migratorios en el norte de Chile. Revista Electrónica Parinas, 2006, II (2), Disponible en Internet: http:// www.unap.cl/p4_inte/site/artic/20060807/ pags/20060807194044.html 
GELBMAN, A. \& TIMOTHY, D.J. Border complexity, tourism and international exclaves: A case study. Annals of Tourism Research, 2011, Vol. 38, № 1, 110-131.

GONZÁLEZ, J.A. La emigración boliviana en la precordillera de la Región de Antofagasta, 1910-1930. Redes sociales y estudios de casos. Revista de Ciencias Sociales, 2008, № 21, p. 61-85.

GONZÁLEZ, S. Cochabambinos de habla quechua en las salitreras de Tarapacá, 18801930. Chungará, Revista de Antropología Chilena, 1995, Vol. 27, № 2, p. 135-151.

GONZÁLEZ, S. Hombres y mujeres de la pampa. Tarapacá en el ciclo de expansión del salitre. Santiago de Chile: LOM, 2002.

GONZÁLEZ, S. El Dios Cautivo. Las ligas patrióticas en la chilenización compulsiva de Tarapacá (1910-1922). Santiago de Chile: LOM, 2004.

GONZÁLEZ, S. La llave y el candado: el conflicto entre Perú y Chile por Tacna y Arica (1883-1929). Santiago de Chile: LOM, 2008.

GONZÁLEZ, S. El Norte Grande de Chile: La definición histórica de sus límites, zonas y líneas de fronteras y la importancia de las ciudades como geosímbolos fronterizos. Revista de Historia Social y de las Mentalidades, 2009a, Vol. 13, N² 2, p. 9-42.

GONZÁLEZ, S. La presencia boliviana en la Sociedad del salitre y la nueva definición de la frontera: Auge y caída de una dinámica transfronteriza (Tarapacá 1880-1930). Chungará, Revista de Antropología Chilena, 2009b, Vol. 41, No 1, p. 71-81.

GUILLÉN, M. Is globalization civilizing, destructive or feeble? A critique of five key debates in the social-science literature. Annual Review of Sociology, 2001, № 27, p. 235-260.

HEVILLA, M.C. El estudio de la frontera en América. Una aproximación bibliográfica. Biblio 3W. Revista Bibliográfica de Geografía y Ciencias Sociales, 1998, № 25. Disponible en Internet: http://www.ub.es/geocrit/b3w-125.htm
HEVILLA, M.C. y ZUSMAN, P. Diez años de estudios de fronteras en los coloquios Internacionales de Geocrítica, 2008. Disponible en Internet: http://www.ub.es/geocrit/xcol/108.htm

HINOJOSA, A. Idas y venidas. Campesinos tarijeños en el norte argentino. La Paz: Fundación PIEB, 2000.

HINOJOSA, A. Bolivia for export. Temas de debate, № 6, 2006.

INSTITUTO NACIONAL DE ESTADISTICAS (INE). Censos de Población. Santiago de Chile: Instituto Nacional de Estadística, varios años.

INSTITUTO NACIONAL DE ESTADISTICAS E INFORMÁTICA (INEI). Perú: Estadísticas de la migración internacional de peruanos 1990-2005. Lima: OIM, 2006.

JAQUET, H. Más allá de la frontera, las fronteras: una aproximación socioespacial a las situaciones fronterizas. En: DILLA, $\mathrm{H}$. (Editora). Ciudades en la frontera: Aproximaciones críticas a los complejos urbanos fronterizos. Santo Domingo: Ediciones Manatí, 2008, p. 33-63.

LEONTIDOU, L.; DONNAN, H. \& AFOUXENIDIS, A. Exclusion and Difference along the EU Border: Social and Cultural Markers, Spatialities and Mappings. International Journal of Urban and Regional Research, 2005, Vol. 29, № 2, p. 389-407.

LLANQUE, J. Qamiris aymaras. Nuevas elites en Oruro. Tinkazos. Revista Boliviana de Ciencias Sociales, 2011, № 29, p. 45-63.

LLOPIS, R. El 'Nacionalismo metodológico' como obstáculo en la investigación sociológica sobre migraciones internacionales. Empiria. Revista de metodología de Ciencias Sociales, 2007, № 13, p. 101-117.

LUQUE, J.C. Asociaciones políticas de inmigrantes peruanos y la "Lima Chica" en Santiago de Chile. Migraciones Internacionales, 2007, Vol. 4, № 2, p. 121-150.

MARTELES, S. Cooperación transfronteriza en la Triple Frontera de Bolivia-Chile-Perú. En: RHI-SAUSI, J. L. y CONATO, D.C. (Edi- 
tores). Cooperación transfronteriza e Integración en América Latina. Roma: IILA/CeSPI, 2009, p. 175-215.

MARTÍNEZ, J. La migración internacional en los censos de población. En: SCHKOLNIK, S. y CHACKIEL, J. (Editores). América Latina: aspectos conceptuales de los censos del 2000. Santiago de Chile: CEPAL, 1999.

MARTÍNEZ, J. El encanto de los datos. Sociodemografía de la inmigración en Chile según el censo de 2002. Santiago de Chile: CEPAL, 2003.

MARTÍNEZ, J. Medición e información sobre la migración internacional a partir de los censos: Lecciones, desafíos y oportunidades. Notas de Población, 2008, p. 97-133.

MEDINA, E. Aportaciones para una epistemología de los estudios sobre fronteras internacionales. Estudios Fronterizos, 2006, Vol. 7, $\mathrm{N}^{\circ} 13$, p. 9-27.

MINISTERIO DE DEFENSA NACIONAL. Ministros de Defensa e Interior encabezaron lanzamiento de Plan Frontera Norte. 2011. Disponible en Internet: http://www. defensa.cl/2011/10/04/ministros-de-defensae-interior-encabezaron-lanzamiento-de-planfrontera-norte/

MINISTERIO DEL INTERIOR. Informe Anual. Departamento de Extranjería y Migración. 2010. Disponible en Internet:

http://www.extranjeria.gov.cl/filesapp/Informe\%20Estimacion\%20Poblacion\%20Extranjeros\%202008.pdf

NAVARRETE, B. La 'quinta oleada migratoria' de peruanos a Chile: los residentes legales. Revista Enfoques, 2007, N 7, p. 173195.

NEWBY, C.A.. Border Crossing and Settlement in El Paso, Texas: Understanding Transborder Actors. Montreal: Annual Meeting, 2006.

NEWMAN, D. The lines that continue to separate us: borders in our 'borderless' world. Progress in Human Geography, 2006, Vol. 30, $\mathrm{N}^{\circ} 2$, p. 143-161.
NICOLAO, J. Migraciones intrarregionales en Sudamérica. 2011. Disponible en Internet: http://www.almendron.com/tribuna/34041/ migraciones-intrarregionales-en-sudamerica/

NORAMBUENA, C. Migraciones limítrofes. Chile 1865-1960. En: ASDRÚBAL, H. (Editor). Historia de las migraciones limítrofes en el Cono Sur de América. Argentina, Bolivia, Brasil, Chile, Paraguay y Uruguay. Vol II Bolivia, Chile, Paraguay y Uruguay. México: Instituto Panamericano de Geografía e Historia, 2002, p. 25-90.

OFICINA CENTRAL DE ESTADÍSTICA. Sesto censo jeneral de la población de Chile. Santiago de Chile: Imprenta de 'La Patria', 1885.

OFICINA CENTRAL DE ESTADÍSTICA. Sétimo Censo Jeneral de la Población de Chile. Valparaíso: Imprenta L. Universo, 1895.

PARELLA, S. Segregación laboral y 'vulnerabilidad social' de las mujeres inmigrantes a partir de la interacción entre clase social, género y etnia. En: SOLÉ, C. y FLAQUER, L. (Editores). El uso de las políticas sociales por las mujeres inmigrantes Madrid: Instituto de la Mujer, 2005, p. 97-117.

PINTO, J. Reclutamiento laboral y nacionalidad: el problema de la mano de obra en los inicios de la industria salitrera (18501879). En: NORAMBUENA, C.E. (Editor). ¿Faltan o sobran brazos? Migraciones internas y fronterizas (1850-1930). Santiago de Chile: Universidad de Santiago, 1997, p. 17-41.

PRIES, L. Migración transnacional y la perforación de los contenedores de Estadosnación. Estudios Demográficos y Urbanos, 2002, No 17 , p. 517-597.

RODRÍGUEZ, M. El trabajo de los extranjeros en Chile y en la I Región. Santiago de Chile: Departamento de Estudios de la Dirección del Trabajo, 2005.

ROZAS, C. Extranjeros en Arica: las reveladoras cifras de la inmigración. La Estrella de Arica, 5 de junio de 2009.

SASSEN, S. Una sociología de la globalización. Buenos Aires: Kast, 2007. 
SASSONE, S. y CORTÉS, G. Cruzar y vivir la frontera entre Bolivia y la Argentina: Entre el Estado y la capital espacial del migrante En: ANGUIANO, M.E. y LÓPEZ, A. M. (Editores). Migraciones y fronteras: nuevos contornos para la movilidad internacional. Barcelona: Icaria Antrazyt/CIDOB, 2010.

SCHIAPPACASSE, P. Segregación residencial y nichos étnicos de los inmigrantes internacionales en el Área Metropolitana de Santiago. Revista Geografía Norte Grande, 2008, No 39 , p. 21-38.

SHAMIR, R. Without Borders? Notes on Globalization as a Mobility Regime. Sociological Theory, 2005, Vol. 23, No2, p. 197-217.

SOLIMANO, A. Globalización y migración internacional: La experiencia latinoamericana. Revista de la CEPAL, 2003, № 80, p. 55-72.

SOLIMANO, A. y ALLENDES, C. Migraciones internacionales, remesas y el desarrollo económico. La experiencia Latinoamericana. En: SOLIMANO, A.C. (Editor). Migraciones internacionales en América Latina. Booms, crisis y desarrollo. Santiago de Chile: FCE, 2008, p. 29-73.
SOLIMANO, A. y TOKMAN, V. Migraciones internacionales en un contexto de crecimiento económico: el caso de Chile. En: SOLIMANO, A.C. (Editor). Migraciones internacionales en América Latina. Booms, crisis y desarrollo. Santiago de Chile: FCE, 2008, p. 185-266.

STEFONI, C. Inmigración peruana en Chile. Una oportunidad a la integración. Santiago de Chile: Editorial Universitaria, 2003.

STEFONI, C. Migración, género y servicio doméstico. Mujeres peruanas en Chile. En: VALENZUELA, M. y MORA, C. (Editores). Trabajo doméstico: un largo camino hacia el trabajo decente. Santiago de Chile: Oficina Internacional del Trabajo, 2009, p. 191.

VAN DER VELDE, M. \& VAN NAERSSEN, T. People, borders, trajectories: an approach to cross-border mobility and immobility in and to the European Union. Area, 2010. Disponible en Internet: http://dx.doi. org/10.1111/j.1475-4762.2010.00974.x

WIMMER, A. y SCHILLER, N.G. Methodological Nationalism, the Social Sciences, and the Study of Migration: An Essay in Historical Epistemology. International Migration Review, 2003, Vol. 37, №3, p. 576-610. 